AperTO - Archivio Istituzionale Open Access dell'Università di Torino

\title{
Assessing Rape Myth Acceptance: A Contribution to Italian Validation of the Measure for Assessing Subtle Rape Myth (SRMA-IT)
}

\section{This is the author's manuscript}

Original Citation:

Availability:

This version is available http://hdl.handle.net/2318/1801624

since 2022-09-20T12:32:25Z

Published version:

DOI: $10.1177 / 10790632211028158$

Terms of use:

Open Access

Anyone can freely access the full text of works made available as "Open Access". Works made available under a Creative Commons license can be used according to the terms and conditions of said license. Use of all other works requires consent of the right holder (author or publisher) if not exempted from copyright protection by the applicable law. 


\title{
Assessing Rape Myth Acceptance: a contribution to Italian validation of the Measure for Assessing Subtle Rape Myth (SRMA-IT)
}

\author{
Mara Martini, Stefano Tartaglia, \\ and Norma De Piccoli \\ Department of Psychology, University of Turin
}

\begin{abstract}
The study aimed to validate the Italian version of the Measure for Assessing Subtle Rape Myths developed by McMahon and Farmer (2011). A sample of 3,915 university students (70.8\% female) completed the questionnaire. After an exploratory factor analysis, a confirmatory factor analysis tested the resulting four-factor structure of the SRMA-IT scale ("She Asked for It”, "He Didn’t Mean To”, “It Wasn’t Really Rape”, “She Lied”), consistent with McMahon and Farmer's initial hypothesis. The Italian validation did not include items related to intoxication. Internal consistency of the subscales was good ( $\alpha$ from .78 to .90). Convergent validity between all subscales and System Justification - Gender was detected: strong relationship was observed ( $r$ is from .19 to .33; $p<.001$ ). The Independent sample $\mathrm{T}$ test then showed that women accepted all four rape myths significantly less than men: effect size is more than moderate for the myth "She Asked for It" (Cohen's $d=.60$ ) and between small and moderate for the other myths ( $d$ is from .35 to .42). Acceptance of rape myths is often associated with higher men's proclivity to rape and with tendency to raped women's double victimization (they can be not believed or blamed when they disclose the rape). Having a validated instrument to measure rape myth acceptance can enhance empirical research on this topic and help to develop interventions of prevention both for men in the society and for the first responders to disclosures, also sustaining a culture of respect and of contrast to violence.
\end{abstract}

Keywords: Rape Myth Acceptance, Italian validation, SRMA-IT, System Justification-Gender, Sexual violence. 


\section{Introduction}

\section{Background}

Gender violence is a major issue across cultures. About 35\% of women worldwide experience either physical and/or sexual intimate partner violence or non-partner sexual violence in their lifetime (WHO, 2018). In 2014, a survey conducted by the European Union Agency for Fundamental Rights (FRA, 2014) estimated that in the EU 13 million women experienced physical violence and 3.7 million women experienced sexual violence during the 12-month period that preceded the survey interviews. One out of three women (33\%) has experienced physical and/or sexual violence since the age of 15. The Italian National Institute of Statistics (ISTAT) survey found that, in Italy, 31\% of women aged 16-70 years experienced some kind of violence during their lifetime, with $20 \%$ experiencing physical violence, 21\% sexual violence, and 74\% sexual harassment (ISTAT, 2015). Moreover, despite a slight reduction in violence as a whole from 2006 to 2014, the number of female victims of extreme violence (rape and attempted rape) in Italy remains stable. The seriousness of sexual and physical violence, then, has increased. Rates of violence against women remains stable and widespread (Il Sole 24Ore, 2019).

In recent decades, international legislation defined gender violence "a violation of human rights” and this statement has been ratified by the legislation of several countries. Civil and penal code mandates, notwithstanding, do not have always a deep impact on social norms affecting gender attitudes and behaviors, including sexual violence, and, even if legislation can contribute to modify the social norms, it takes very long time (WHO, 2009). Several studies show that the enduring prevalence of sexual violence across societies may be explained by the existence of shared social norms justifying the sexual aggressions (Edwards, Turchik, Dardis, Reynolds, \& Gidycz, 2011; Hinck \& Thomas, 1999; Payne, Lonsway, \& Fitzgerald, 1999) and reducing the willingness to support victims or to punish perpetrators (Chapleau \& Oswald, 2014; Eyssel \& Bohner, 2011). One pervasive social norm is that woman has to protect their virtue, to play the "dual role as temptress and regulator" 
(Block, 2006; p. 39) while man has to be the conqueror and to break down woman's resistance (Edwards et al., 2011). In this frame, if a woman does not protect enough her virtue with adequate clothing or does not oppose physical resistance to sexual attempt, she is considered in some way guilty for having been raped.

False representations and legitimations of gender violence are analyzed in terms of Rape Myths (Lonsway \& Fitzgerald, 1995). In order to measure acceptance of rape myths in Italian context, the aim of the present study is to validate the Italian version of the Measure for Assessing Subtle Rape Myths (McMahon \& Farmer, 2011). In this direction, a brief analysis of the Italian socio-cultural context is given below.

\section{The Italian context}

In Italy, legislation has shown some consideration of the issue of gender violence in recent years. By establishing "Provisions against sexual violence,” Law no. 66 of 1996 turned the crime of sexual abuse into a crime against the person, introducing the crimes of sexual violence, sexual acts with children and gang rape. Before the sexual abuse was considered a crime against morality. Among others, Law no. 38 of 2009 increased the punishment for sexual acts and introduced stalking as an offense punishable by imprisonment. Law no. 93 of 2013 defines stricter punishments and improves tools to protect victims.

However, stereotypical representations attributed to the woman's expected role in the social context persist to date. A recent survey of the European parliament (Eurobarometer, 2015) reported that $72 \%$ of Italians believe that "when the mother has a full-time job, family life suffers" (the European average is 60\%). Moreover, according to data collected by Craig and Mullan (2011), Italian women dedicated more time (one hour and more) to domestic work compared to other countries examined (11 European countries, US, Canada, Australia). The ISTAT (2015) survey revealed that women are reported generally satisfied with the division of domestic work. These data express how 
deeply traditional gender roles are still rooted in Italian culture and suggest that such gender models might be transmitted to new generations.

Finally, a recent report of the World Economic Forum measuring gender equality in 20 European countries ranked Italy in the last positions followed only by Greece, Cyprus and Malta (Global Gender Gap Report, 2018). Therefore, in Italy, gender roles still appear to be strongly rooted in culture (Caraballese et al., 2014). These may induce women to accept a certain degree of violence to keep the family together and respond to social expectations (Filippini, 2005; Cravens, Whiting, \& Aamar, 2015). Attitudes based on gendered traditional role are reinforced by beliefs about the validity

of the system. Moreover, as Selvatico (2018) explains, the victim of sexual violence may feel ashamed because of making public something that is culturally believed to be a private affair between herself and the perpetrator. In any case, again, social judgement usually falls on the victim rather than the perpetrator.

\section{Rape myths}

Since the origin of the concept of rape myths in the 1970s (Brownmiller, 1975; Schwendinger \& Schwendinger, 1974), research about this issue is divided into two main trends: the feminist one (from Brownmiller, 1975) and the sociological one (from Schwendinger \& Schwendinger, 1974). The latter was further developed by social psychologists (from Burt, 1980).

The feminist approach considers rape myths mainly based on the patriarchal system sustaining the power of men over women; these “false representations” are supported by ideologies expressed by legal, media and religious institutions (Edwards et al., 2011). This approach is mainly focused on rape myths centered on misconceptions about female sexuality and on the power relationship between men and women. For example, Payne and colleagues (1999) affirm that our social culture does not recognize as a crime husband' sexual coerciveness towards his wife, because marriage is equated with perpetual sexual consent, and men possess a degree of ownership over their wives. Another myth underscored by this approach is "Many women secretly desire to be raped (so it is not such a big 
crime).” Women should not openly express their sexual desire and they have to say "no" to mean “yes,” and when they say "no” they are actually asking for sex. Moreover, if the woman says "no,” but she does not physically resist, it is not really a rape (Bond \& Mosher, 1986).

The social psychological approach to rape myths emphasizes the similarities with stereotypes (Chapleau \& Oswald, 2010; 2014). According to Lonsway \& Fitzgerald (1995), "Rape myths are attitudes and beliefs that are generally false but are widely and persistently held, and that serve to deny and justify male sexual aggression against women” (p. 134). It draws attention to the process of sharing society's false beliefs by making them sound normal with the consequences of reducing the perception of the severity of sexual abuse. Their function is to protect self-esteem by attributing the role of potential rapist or victim to others; often these "others" are perceived as far from their own relational world, for example a member of an out-group. One myth highlighted by this approach is the idea that male sexual instincts cannot be controlled at times. In other words, he is actually not to be blamed for the action because it is in his nature. Another myth considers that rape happens only in certain situations or to some kinds of people. For example, rape more readily occurs to women who dress “provocatively,” but if you adequately cover your body, no one will bother you (Edwards et al., 2011).

Women and men usually show different levels of rape myth acceptance (Mc Mahon \& Farmer, 2011). This result is quite consistent across studies that used either older or updated versions of tools designed to measure rape myth acceptance (Payne et al., 1999; Mc Mahon \& Farmer, 2011). It is also confirmed by studies conducted in different cultural contexts: China (Xue et al., 2016), Korea (Ho \& Neville, 2004); US, Japan and India (Stephens, Kamimura et al., 2016); Norway (Bendixen \& Kennais, 2017) and India (Kamdar, Kosambiya, Chawada, Verma, \& Kadia, 2017).

Though women usually resist stereotypes about sexual violence more than men, it is quite striking that women accept rape myths to some extent. Indeed, these false beliefs about sexual aggressions lead to dual victimization of women, firstly, because they are victims of male sexual assaults, and secondly, because they are blamed of having provoked the violence in some way. 
It is hard to recognize forms of violence and discrimination, since stereotypes about sexual violence are common in the socio-cultural context. Gender-based aggression and harassment become invisible to the eyes of society, to men and women alike, who are, therefore, less aware of the prevalence of violence and discrimination against women. Consequently, unfairness in gender relationships is less often perceived. This is what Jost and Kay (2005) call Gender-specific system justification. System justification theory refers to the acceptance of aspects of a social system that are objectively unjust: in other words, it is within the interests of the system to justify and support the status quo. One important aspect of this theory is that even disadvantaged groups justify the system, even though the same system designates their role as a subordinate group (Jost \& Kay, 2005).

Acquiescence to system justification could explain why women accept rape myths to some degree (Jost \& Banaji, 1994; Chapleau \& Oswald, 2013); moreover, it is functional to sustain and justify the status quo of inequality in relationships between men and women (Chapleau \& Oswald, 2013; 2014; Stahl, Eek, \& Kazemi, 2010). Indeed, Chapleau and Oswald (2014) notice a high degree of correlation between rape myth acceptance and justification of gender inequality. According to the System Justification Theory (Jost \& Banaji, 1994; Jost, \& Kay, 2005), all members of a society identify with the current culture (the status quo) to some extent. Even if this culture favors one group more than another one, and a change could enhance subordination of one group, both dominant (male - in the Gender-specific system) and subordinated (female) groups are inclined to defend it (Chapleau \& Oswald, 2013; Jost \& Banaji, 1994) as a central component of their own identity. Hence, a threat from the cultural system is distressing for people who belong to it (Jost \& Banaji, 1994). Seeing that the system either penalizes or unfairly treats somebody or a certain group (women) can generate embarrassment or dissonance and undermine trust in the system itself. As members of both dominant and subordinate groups need to reduce the dissonance, they resort to stereotypes, which claim that inequality either is a natural condition or is “deserved” by the subordinated group. Subsequently, if something, such as reports of rape or discrimination, threatens the status quo, they blame the person who reports it by stating that the victim deserved the violence, thus weakening the system even more 
than the perpetrator did (Chapleau \& Oswald, 2013). This process can explain the enduring justification of gender violent actions and difficulties distinguishing them.

\section{Measurement of rape myths}

Several tools have been developed to both identify and measure how rape myths are represented within social and cultural frameworks. One of the first instruments to measure rape myth acceptance is the Rape Myth Acceptance scale (RMA), developed by Burt (1980), considering in its three factors (19 items) social psychological, feminist theory, and demographic dimensions of stereotypical beliefs on rape (Jones, Russell, \& Bryant, 1998; Reddy, 2018).

Another, quite recent and long, instrument to measure rape myth acceptance, is the Acceptance of Modern Myths about Sexual Aggression scale (AMMSA), proposed in English and Dutch, composed of 30 item (Gerger, Gerger, Kley, Bohner, \& Siebler, 2007).

Widely used is notwithstanding the Illinois Rape Myth Acceptance scale (IRMA) designed by Payne and colleagues (1999). It consists of 45 items grouped into seven subscales that represent components of rape myth acceptance, namely: 1 . She asked for it; 2 . It wasn’t really rape; 3. He didn’t mean to; 4. She wanted it; 5. She lied; 6. Rape is a trivial event; 7. Rape is a deviant event. This version was structurally the same across genders, even if it measured a different degree of acceptance of rape myths between men and women, consistently across the previous literature. The IRMA scale developed in 1999 remains in use (Edwards et al., 2011) and is one of the most widely employed scales to assess the persistence and prevalence of false conceptions of sexual assault across different cultures (Xue et al., 2016).

The need for cultural adaptation of the instrument, therefore, cannot be disregarded (Arafat, Chowdhury, Qusar, \& Hafez, 2016). Tools that measure acceptance of rape myths must be adapted to suit both cultural sensitivity (McMahon \& Farmer, 2011) and the specific national context (Xue et al., 2016). Subsequently, adaptation and validation of tools that measure rape myths are highly recommended. 
Following this trend, Xue and colleagues (2016) adapted and translated the IRMA scale to assess rape myth acceptance among a sample of Chinese university students. Psychometrically, they deleted 20 items and generated a five-factor model. The Chinese scale confirmed that female students endorse rape myth statements to a lesser degree than male students, as is consistent with many studies conducted in other countries. Stephens and colleagues (2016) compared male and female college students in the US, Japan, and India by using the first 11 items of the original Rape Myth Acceptance Scale (Burt, 1980). They found that rape myth acceptance varies by country. Lee (1999) proposed a Korean version of Burt's Scale (1980) to detect representation of rape in the Korean context. Ho and Neville (2004) further modified and integrated it to explore rape beliefs in Korean culture more effectively.

However, even adaptation can become outdated for measuring expressions of cultural contexts (McMahon \& Farmer, 2011). Some phrases, especially colloquial expressions, can be either less known or common among today’s responders, particularly for younger subjects. Moreover, changes in social culture can result in modified acceptance of some myths or of phrases that convey them. In this regard, an educational intervention to fight sexual violence in schools, universities, and society can play an important role. McMahon and Farmer (2011) observed that social acceptability of certain misconceptions has changed, and that many people who still agree with some of the myths measured by the IRMA scale do not feel free of declare it (social desirability bias; Tourangeau, Rips, \& Rasinski, 2000). Hence, today the acceptance of rape myths is perhaps more subtle, and an effective tool to measure it must detect the elusive expressions of acceptance that remain. McMahon and Farmer (2011) proposed an updated shorter version of the IRMA scale to assess Subtle Rape Myths: the Updated Measure for Assessing Subtle Rape Myths. After changing some words and some sentences of IRMA, this measure demonstrated a four-factor structure: 1. She asked for it; 2 . He didn’t mean to; 2bis. He didn’t mean to (intoxication) 3. It Wasn't really rape; 4. She lied. This tool was empirically evaluated and used in several different countries. McMahon and Farmer's Updated Measure for Assessing Subtle Rape Myths was considered overall, without taking into account the 4 
subscales described in the original version, in a Norwegian study involving 1,713 students in a Webbased questionnaire. Data revealed that men, less than women, disapproved of stereotypical beliefs, and that only men thought that rape stereotypes predicted harassment of peers of both sexes (Bendixen \& Kennair, 2017). Navarro and Tewksbury (2017) surveyed Rape Myth Acceptance in 727 university students from 21 U.S. institutions. In this sample too, males and younger respondents showed higher rape myth acceptance, and gender was a predictor for all five subscales of the Measure to Assess Subtle Rape Myths. This study found 5 subscales, “She asked for it”; “He didn’t mean to”; “He didn’t mean to - Intoxication questions”; “It wasn’t really rape,” “She lied.”

Kamdar and colleagues (2017) in India used the Updated Measure for Assessing Subtle Rape Myths involving 332 students. Data indicated that rape myths were generally higher among youth and males but no psychometric comparisons were performed by this study, and no reflections were made regarding validity in the Indian cultural context. To our knowledge, the tool proposed by McMahon and Farmer (2011) has not yet been validated in contexts other than the US. Nevertheless, as mentioned above, cultural contextualization is necessary, since representations, perceptions and gender stereotypes are also cultural co-constructions.

\section{Current study}

To the best of our knowledge, this tool has not yet validated in Italian. Thus, this paper intend to propose the first Italian adaptation and validation of the Updated Measure for Assessing Subtle Rape Myths by McMahon \& Farmer (2011): Italian Subtle Rape Myth Acceptance scale (SRMA-IT). This version of the tool was chosen due to its shorter length than the original IRMA scale (Payne et al., 1999), and its greater suitability for measuring the subtle forms of stereotypes. Despite its brevity notwithstanding, it examines a number of false beliefs about sexual violence.

This study also wanted to explore relationships with the System Justification-Gender scale (Jost \& Kay, 2005) in order to confirm, in line with previous studies (e.g. Chapleau \& Oswald, 2014), the hypothesis (H1) that acceptance of rape myths strongly correlate with system justification gender. 
Finally, this work intended to determine if women and men show different levels of rape myth acceptance. Consistentl with previous studies (e.g. Navarro \& Tewksbury, 2017), our hypothesis (H2) was that beliefs in rape myths are higher in men than in women.

\section{Method}

\section{Procedure}

The Updated Measure for Assessing Subtle Rape Myth proposed by McMahon and Farmer (2011) was translated into Italian in a previous study (Rollero \& Tartaglia, 2018), which did not presented notwithstanding its validation. For the present study, six researchers in psychology, sociology, and law independently checked and verified the translation. These six scholars compared the different revisions, and when they were discordant on some points, they discussed them until they reached agreement. They achieved consensus on the version provided in Table 1 . The scale was then included within a wider questionnaire that was submitted to the Bioethics Committee of our University (Approval N.234687, 20th October 2016).

A pre-test was conducted with a small group of students $(\mathrm{N}=143)$ who completed a paper format version of the questionnaire. The primary investigator was present in the classroom when students completed the questionnaire in order to explain or clarify unclear items. Students did not express difficulties with understanding items of the SRMA-IT scale. They were 51.7\% women and 48.3\% men; a great part (97.2\%) was attending their first year at the university. The majority (98.6\%) were not married, and no one had children; most lived with their parents (56\%) or with flat mates (34.8\%). Cronbach’s alpha was used to assess internal consistency of the SRMA-IT scale. McMahon and Farmer (2011) reported $\alpha$ values for the whole scale of .91 and for the four subscales $\alpha$ values ranged from .73 to .89 for the current study, suggesting good internal reliability for the Italian version of the scale in the test sample.

Data for the present study were collected using the LimeSurvey platform for online surveys between December 2016 and March 2017. The sample included students from two public universities 
in Turin, Italy. After the two universities’ Rectors' approval, and with the assistance of Student Services offices, an e-mail describing the research project and inviting them to complete the online questionnaire, by opening the attached link, was sent students. Participation was voluntary and anonymous. Before starting the questionnaire, students had to read and complete informed consent documentation. Anonymity of both data and findings was ensured. The study was jointly conducted with the USVreact (Universities Supporting Victims of Sexual Violence) project ${ }^{1}$, which had the purpose to develop innovative training for university staff who may respond to disclosures of sexual violence.

\section{Participants}

The participants to the survey were 4095 but 90 questionnaires were not completed and were eliminated. The final sample included 4005 university students: 2,987 students from the University of Turin and 1,018 students from the Polytechnic University of Turin. Most (70.8\%) participants were females, with $29.2 \%$ male. The average age was 22.67 years ( $S D$ 4.85). Among respondents, 32.7\% were attending the first year of university, $22.4 \%$ the second, $16.1 \%$ the third, and the residual $28.4 \%$ were in their fourth year or more. Moreover, $94.6 \%$ were not married, $4.9 \%$ are married or live with their partners, $0.5 \%$ are separated, divorced or widowed. The majority (98.3\%) had no children. In the end, $56.6 \%$ lived with their parents, $26.5 \%$ with flat mates, $7.1 \%$ alone and $3.6 \%$ in student residences.

In order to explore and confirm the structure of SRMA-IT scale, the larger sample was randomly divided into training $(N=2,041)$ and a validation $(N=1,964)$ samples, maintaining distribution proportions for gender and age of the whole sample in both the training and validation samples.

\section{Measures}


The questionnaire developed for the survey included the following indicators used in the analyses:

- The Updated Measure for Assessing Subtle Rape Myth (McMahon \& Farmer, 2011) consisting of 22 items on a five-point Likert-type response scale ranging from 1 = "Strongly disagree" to 5 = "Strongly agree.” The 22 items were grouped into 4 subscales. The first subscale, "She asked for it” (6 items), referred to the false idea that an assaulted woman actually provokes the rape with her behaviour; an example item is "When girls go to parties wearing slutty clothes, they are asking for trouble.” The second subscale, “He didn’t mean to” (6 items), reflected the belief that the rapist did not intend to assault the woman but was unable to avoid it; an example item is "Rape happens when a guy's sex drive gets out of control.” The third subscale, “It wasn't really rape” (5 items), included statements that seemingly minimize the severity of rape, justifying the perpetrator's behavior; an example item is “If a girl doesn’t physically resist sex - even if protesting verbally - it can’t be considered rape.” The fourth subscale, "She lied” (5 items), expressed the stereotype that many disclosures are actually invented by women as an excuse; an example item is "Girls who are caught cheating on their boyfriends sometimes claim that it was a rape”. In their validation study (2011) McMahon and Farmer identified a fifth sub-factor called "He didn’t mean to because of intoxication”. This factor was made up of the three items of subscale 2 considering the effects of alcohol as a justification for sexual assault; an example item is "If a guy is drunk, he might rape someone unintentionally.”

- The System Justification - Gender (Jost \& Kay, 2005) scale. It consists of 8 items on a Likert answer scale ranging from 1 (“strongly disagree”) to 9 (”strongly agree”). It measures to what extent respondents believe that the system of gender relations is equal and fair in their cultural and social context. An example item is "In general, relations between men and women are fair.”

- A list of sociodemographic items (gender, age, marital status, having children, where they live). 
Moreover, the questionnaire included a set of items investigating the knowledge of the public services supporting victims of sexual violence. These items were inserted in the survey for planning of informative campaigns and these indicators were not used in the validation analyses here reported.

\section{Statistical Analyses}

After descriptive analyses of single items, an exploratory factor analysis was performed of the whole scale to assess the SRMA-IT structure. Then, a confirmatory factor analysis was carried out to test the resulting structure. For convergent validity between the SRMA-IT subscales and the System Justification - Gender scale, a measure known to be associated with rape myths, was also checked. Differences between men and women in terms of Rape Myth Acceptance was then analyzed with an Independent Sample T test. Effect size was then calculated by Cohen's d; Cohen (1988) indicates that the strength of the effect size is small if $d=.20$, moderate if $d=.50$ and large if $d=.80$. Software SPSS version 24 was used for the exploratory factor and convergent validity analyses, whereas for the confirmatory factor analysis the software AMOS version 20 was used because it allows the test of structural equation models, not performed by SPSS.

\section{Results}

\section{Descriptive statistics on single items}

Descriptive statistics on single items (Table 1) performed on the training sample $(N=2041)$ showed poor agreement with the 22 statements of the scale (i.e. no item displayed $M$ value higher than 2.61 on 1-5 range). Higher values of agreement $(M>2.30)$ were for items that express some women's responsibility (through their behavior) in being the victims of rape ("If a girl initiates kissing or hooking up, she should not be surprised if a guy assumes she wants to have sex”), and for items that reduce the man’s guilt ("Rape happens when a guy’s sex drive gets out of control”).

\section{Exploratory factor analysis}


A maximum likelihood factor analysis with Oblimin rotation explored the factor-based structure of Updated Measure for Assessing Subtle Rape Myth. Four factors had eigenvalues higher than one. The number of factors was consistent with the theoretical structure observed in focus groups conducted by McMahon and Farmer (2011). The factor structure after rotation (see Table 2) closely resembled the original one. There were only two items that loaded on a different factor, as compared to the theoretical structure. The items “It shouldn't be considered rape if a guy is drunk and didn't realize what he was doing” and "If both people are drunk, it can’t be rape” loaded on the factor "It Wasn’t Really Rape,” instead of the factor “He Didn’t Mean To.” McMahon and Farmer (2011) included these two items in a fifth factor called “He Didn’t Mean To (intoxication).” Exploratory factor analysis conducted on our sample did not support a five-factor based structure because the fifth factor had eigenvalues lower than one. Therefore, we decided not to include these two items in the subsequent analyses. The resulting four subscales were consistent with the theory on Rape Myths and showed good internal consistency: "She Asked for It" (6 items; $\alpha=.80)$, "He Didn’t Mean To” (4 items; $\alpha=.78$ ), “It Wasn’t Really Rape” (5 items; $\alpha=.87$ ), "She Lied” (5 items; $\alpha=.90$ ).

\section{Confirmatory factor analysis}

A confirmatory factor analysis (maximum likelihood procedure; covariance matrix) was conducted on the validation sample by testing a structural equation model based on the four-factor structure. As recommended (Hu \& Bentler, 1999), model fit was tested by using different fit indexes to reduce the impact of their limits. The indexes $\chi^{2}$, CFI (Comparative Fit Index; Bentler, 1990), TLI (Tucker-Lewis Index; Tucker \& Lewis, 1973) and RMSEA (Root Mean Square Error of Approximation; Steiger, 1980) were used. For CFI and TLI, values higher than 0.90 are considered satisfactory (Bentler, 1990). For RMSEA, values lower than 0.08 are considered to be satisfactory (Browne, 1990).

The model proved acceptable according to all fit indexes except $\chi^{2}: \chi^{2}(164)=1955.01, p<.01$, $\mathrm{CFI}=.91, \mathrm{TLI}=.90, \mathrm{RMSEA}=.075\left(90 \% \mathrm{CL}=.072\right.$.078). Given that the significance of $\chi^{2}$ depends 
on the sample size and that our sample was quite large $(N=1,964)$, this model can be considered satisfactory. All estimated parameters were significant. Table 3 reports factor loadings and error variances. All factors correlated with each other ( $r$ values ranging from .41 to .60).

\section{Convergent validity}

Relations between the four subscales of SRMA-IT and other key variables known to be associated with the acceptance of Rape Myths were investigated. Gender differences were first tested using the $T$ test for independent samples. Males had higher values on all subscales of Rape Myths acceptance as compared to women (Table 4). The highest values are on the "He didn't mean to" subscale (Males’ $M=2.56$, Females’ $M=2.14$ ) whereas the lowest are on the "It wasn't really rape” subscale (Males’ $M=1.59$, Females' $M=1.35$ ). The $T$ test for independent samples showed that differences between men and women were significant for all the subscales. The strongest effect size was for the subscale "She asked for it" (Cohen's $d=.60$ ), The smallest one was for the "It wasn't really rape” subscale $(d=.35)$.

Correlations between Rape Myths and System justification - gender were then calculated. All correlations were significant. System Justification positively correlated with "She asked for it" $(r=$ .33, $p<.001)$, "He didn’t mean to" $(r=.23, p<.001)$, "It wasn’t really rape” $(r=.19, p<.001)$, and She lied $(r=.22, p<.001)$. Finally, correlations between Rape Myths and age were calculated. Two subscales correlated significantly with the age of participants: "She asked for it" $(r=-.07, p<.01)$ and “He didn’t mean to” ( $r=-.07, p<.01)$. In both cases, the rape myth acceptance was inversely related to age.

\section{Discussion and conclusion}

Our aim was to provide the first validation of the Italian version of the Updated Measure for Assessing Subtle Rape Myth (McMahon \& Farmer, 2011), or the SRMA-IT scale. As rape myths are 
false beliefs about gender violence in social contexts and are deeply interlaced with culture, they are not easily recognizable (Edwards et al., 2011). A tool that assesses rape myths and their acceptance must be able to detect their subtle nuances too. By updating the older and widely used IRMA (Payne et al., 1999), McMahon and Farmer (2011) intended to represent less evident and socially acceptable expressions of rape-related stereotypes. Moreover, as the social and cultural framework influences the development and persistence of the rape myths, it is important to validate the tools in other countries to support cross-cultural comparisons. Therefore, the Italian validation of McMahon and Farmer’s measure have been here presented.

The factorial structure of the 22 item-scale was explored and the four-factor structure was verified by means of a confirmatory factor analysis. The four dimensions are consistent with McMahon and Farmer's initial hypothesis. They express various facets of false beliefs about sexual violence, focusing on the responsibility attributed to woman for her "provocative” behavior ("She asked for it”), on the man’s non-intentionality (“He didn’t mean to”), on conditions to identify a rape (“It wasn’t really rape”), and on women’s instrumental report of rape (“She lied”).

McMahon and Farmer identified an additional fifth subscale including three items that justify the rape because of the perpetrator's (and victim's) intoxication (10, 11, and 12 in Table 1). Our exploratory factor analysis, however, did not support the five-factor structure, and the two alcoholrelated items loaded on different subscales, as compared to the original four-factor structure. These differences could be explained by cultural variations associated with alcohol abuse. The phenomenon of alcohol abuse in students, especially during weekends (i.e. "binge drinking”) has spread throughout the US for several decades, and it has been associated with several episodes of sexual assault on university campuses (Hingson, Zha, \& Weitzman, 2009). However, in Italy “binge drinking” among students is less prevalent (Tartaglia, Fedi, \& Miglietta, 2017). Moreover, in Italy public opinion associates binge drinking most often with the risk of vehicular accidents or damage to health, rather than the risk of rape (DiGrande, Perrier, Lauro, \& Contu, 2000; Laghi, Baiocco, Lonigro, Capacchione, \& Baumgartner, 2012). The Italian mass media often indicate the victims’ behavior 
(that could induce violence) or men’s sexual and psychological "nature” as possible reasons (and justification) for sexual violence. These expressions of patriarchal culture, which are still present in Italian societies, likely contribute to the maintenance of both acceptance of subtle rape myths and belief in the gender relations system's equality. At least, it might account for the strong relationship between System justification - gender and all subscales of the Assessing Subtle Rape Myth scale, confirming our hypothesis $\mathrm{H} 1$ of acceptance of strong correlation between rape myths and system justification gender.

Even if our sample did not reveal high levels of either justification or acceptance of rape myths, the relationship between the two dimensions confirms that justifying a rape myth means considering the social system equal for both genders (male and female), as is consistent with previous studies (Leanna \& Mindy, 2017). This evidence may be explained by the construct of "Belief in a Just World" (Lerner, 1971). Correia, Alves, Morais, \& Ramos (2015) maintained that some people need to believe that the world is a just and fair place, and if a rape occurs, they (both men and women) think that it probably has a reason or justification.

$T$ test analyses detected differences in acceptance of all four dimensions of the rape myths scale between men and women. Consistent with System Justification Theory (Chapleau \& Oswald, 2013), both men and women, as members of the same culture, expressed some degree of agreement with stereotypes about gender violence, but as (potential or actual) victims of violence, women accept rape myths to a lesser degree than men do. These results confirm our hypothesis H2 that rape myths acceptance is higher in men compared to women and, from a psychometric perspective, support the convergent validity of the tool's Italian version.

\section{Limitations}

The study does have some limitations, however. Participants live in the same part of Italy. Future use of these instruments should involve people from other regions within the country. Moreover, research involved only university students. We chose these participants to remain 
consistent with McMahon and Farmer’s (2001) study and because students are young citizens who will play key roles in society, politics, and the workforce. Hence, analyzing their representations and beliefs about rape can be an important first step towards promoting a culture that counteracts violence. Anyhow, proposing the scale to other groups of citizens could be of interest for intergenerational and cultural comparisons. Another limitation of the study is the composition of the sample, which was majority female. Even from a psychosocial point of view, this information is interesting, because it suggests that women are more sensitive to issues of sexual violence and were more available to complete the questionnaire than men. Furthermore, future studies should use the Measure for Assessing Subtle Rape Myth in association with other variables in order to better explore possible antecedents and effects of agreement with stereotypes about sexual violence. In particular, in our study, social desirability that could affect answers on topics of acceptance of rape myths and of perception of fairness in gender relationships had not been measured.

Moreover we found low average values for all the items of the scale. This result may be reassuring, because suggests that rape myths are not strongly prevalent among university students in Turin, but, from a statistical point of view, it indicate the risk of "floor effect" (Catts, Petscher, Schatschneider, Sittner Bridges, \& Mendoza, 2009) for the Italian version of the scale.

\section{Implications}

In spite of these limitations, these findings are valuable because they provide a version of the Measure for Assessing Subtle Rape Myth (by McMahon \& Farmer, 2001) suitable for the Italian context, which is still characterized by a largely sexist culture. The rape myths acceptance can be a predictor of violent behaviors, including its recidivism (Helmus, Hanson, Babchishin, \& Mann, 2013). The SRMA-IT may be useful for primary intervention against sexual violence allowing to identify the populations more prone to accept rape myths guiding the specific intervention against 
sexism and rape myths acceptance. Moreover, it may be used for treatment of sex-offenders too (Olver, Nicholaichuk, Kingston, \& Wong, 2014). Since the treatment leads to a reduction of cognitive distortions and sexual recidivism (Nunes, Pettersen, Hermann, Looman, \& Spape, 2016), measurement of rape myth acceptance could constitute a tool, among others, functional to verify the outcomes of treatment with sex-offenders, both in primary and in tertiary prevention interventions. In fact, some studies showed that sexual offenders report higher endorsement of cognitive distortions compared with who have not sexually offended (e.g., Mann, Webster, Wakeling, \& Marshall, 2007; Whitaker et al., 2008) and that cognitive distortions predict sexual recidivism (Helmus, Hanson, Babchishin, \& Mann, 2013). Rape myth acceptance too is a form of cognitive distortion aimed to justify for sexual violence. Some longitudinal studies highlighted that rape myth acceptance was a significant predictor of sexual violence (Mouilso \& Calhoun, 2013; Warren, Swan, \& Allen, 2015); Grubb and Turner (2012) evidenced that high acceptance of rape myth is associated with higher rape proclivity and with rapists' tendency to justify their violent disposition.

Developing prevention programs to contrast false beliefs about rape and to enhance a culture of contrast to violence could reduce perpetrators’ legitimizing of their sexual assault. Moreover, Grubb and Turner (2012), evidence that acceptance of rape myth is also associated with the tendency either not to believe to rape disclosures, overestimating the number of false rape allegations or blaming the victim for having being assaulted: in both cases, the ill effect is raped woman's double victimization. Training programs for professional rape first responders, trying to contrast rape myth acceptance could allow offering victims of rape to be trusted and adequately supported. Both kinds of program can be important actions of tertiary prevention to sexual violence.

Prevention may be very important in the university too. In several countries (e.g., US and Britain), the prevalence of campus sexual assault is terribly high (e.g. from 20 to $40 \%$ of female students has been a victim of sexual abuse; Cantor, Fisher, Chibnall, Townsend et al., 2015; Stenning, Mitra-Kahn, \& Gunby (2013) and measuring ) acceptance of rape myths, is an emergency in order to counteract them. In Italy the prevalence of rapes on the university campuses is lower, but analyzing 
cultural representation of sexual violence and of gender relationships is also important for understanding to the extent to which the culture that legitimizes gender violence has spread. Legitimizing gender violence can mean tolerating and sometimes failing to recognize less extreme forms of sexual harassment, and, as a consequence, doing nothing to counteract them. It is, therefore, a priority to measure representations of rape in university contexts, since the charge of universities is to educate young citizens and to promote respect for human rights both in their present (as students) and in their future (as workers, politicians, parents). Moreover, this scale could be used as a tool to measure attitudinal change after a training or intervention. In Italy, schools and universities offer a wide choice of training programs, but unfortunately, training efficacy is seldom assessed. We believe that research and intervention constitute two interconnected needs, as Kurt Lewin (1946) argued: research allows assessing interventions while action is an opportunity to study attitude changes in the real social contexts. This interconnection can be fruitfully studied related to sexual violence, as stereotypes and attitudes are a prelude to violent behaviors, and social behaviors can influence beliefs and attitudes.

\section{Footnotes}

${ }^{1}$ Project 'USVreact. Universities Supporting Victims of Sexual Violence: Training for Sustainable Services’ (project code: JUST/2014/RDAP/AG/VICT/7401; duration: March 2016-2018; website: http://usvreact.eu/). Funded with support from the European Commission’s DG Justice, Rights, Equality and Citizenship Programme (DAPHNE strand). This publication [communication] reflects the views only of the author, and the Commission cannot be held responsible for any use that may be made of the information contained therein.

Compliance with Ethical Standards 
This study was funded by the European Commission’s DG Justice, Rights, Equality and Citizenship Programme (DAPHNE strand), project code: JUST/2014/RDAP/AG/VICT/7401.

The author(s) declare that there are no potential conflicts of interest with respect to the research, authorship, and/or publication of this paper.

All procedures performed in studies involving human participants were approved by the Bioethics Committee of the University of Turin (Approval N.234687, 20th October 2016) and are in accordance with the 1964 Helsinki declaration and its later amendments.

Informed consent was obtained from all individual participants included in the study.

\section{References}

Arafat, S. M. Y., Chowdhury, H. R., Qusar, M. M. A. S., \& Hafez, M. A. (2016) Cross-cultural adaptation and psychometric validation of research instruments: A methodological review. Journal of Behavioral Health, 5(3), 129-136. doi: 10.5455/jbh.20160615121755

Bendixen, M., \& Kennair, L. E. O. (2017). Advances in the understanding of same-sex and oppositesex sexual harassment. Evolution and human behavior, 38(5), 1-9. doi: 10.1016/j.evolhumbehav.2017.01.00

Bentler, P. M. (1990). Comparative fit indexes in structural models. Psychological Bulletin, 107, 238246. doi:10.1037/0033-2909.107.2.238

Block, S. (2006). Rape and sexual power in early America. Chapel Hill: University of North Carolina Press.

Bond, S. B., \& Mosher, D. L. (1986). Guided Imagery of Rape: Fantasy, Reality, and the Willing Victim Myth. The Journal of Sex Research, 22(2), 162-183. doi: 10.1080/00224498609551298 
Browne, M. W. (1990). Mutmum Pc: user's guide. Columbus: Ohio State University, Department of Psychology.

Brownmiller, S. (1975). Against Our Will: Men, Women and Rape. New York: Simon \& Schuster.

Burt, M. R. (1980). Cultural Myths and supports for rape. Journal of Personality and Social Psychology, 38 (2), 217-230. doi: 10.1037/0022-3514.38

Cantor, D., Fisher, B., Chibnall, S., Townsend, R., Bruce, C., Thomas, G., \& Lee, H. (2015). Report on the AAU (Association of American Universities) Campus Climate Survey on Sexual Assault and Sexual Misconduct (September 21). Westat: Rockville, Maryland.

Carabellese, F., Tamma, M., La Tegola, D., Candelli, C., \& Catanesi, R. (2014). Women Victims of Violent Partners: The Italian Situation Amid Culture and Psychopathology. Journal of Forensic Science, 59(2), 533-539, doi: 10.1111/1556-4029.12347

Catts, H. W., Petscher, Y., Schatschneider, C., Sittner Bridges, M., \& Mendoza, K. (2009). Floor effects associated with universal screening and their impact on early identification of reading disabilities. Journal of Learning Disability, 42(2): 163-176. doi: 10.1177/0022219408326219

Chapleau, K. M., \& Oswald, D. L. (2010). Power, sex, and rape myth acceptance: Testing two models of rape proclivity. Journal of Sex Research, 47, 66-78. doi:10.1080/00224490902954323

Chapleau, K. M., \& Oswald, D. L. (2013). Status, Threat, and Stereotypes: Understanding the Function of Rape Myth Acceptance. Social Justice Research, 26(1), 18-41. doi: 10.1007/s11211-013-0177-z

Chapleau, K. M., \& Oswald, D. L. (2014). A system justification view of sexual violence: legitimizing gender inequality and reduced moral outrage are connected to greater rape myth acceptance. Journal of Trauma \& Dissociation, 15(2), 204-18. doi: $10.1080 / 15299732.2014 .867573$

Cohen, J. (1988). Statistical Power Analysis for the Behavioral Sciences (2nd edn.), Hillside, NJ: Erlbaum. 
Correia, I., Alves, H., Morais, R., \& Ramos, M. (2015). The legitimation of wife abuse among women: The impact of belief in a just world and gender identification. Personality and Individual Differences, 76, 7-12. doi: 10.1016/j.paid.2014.11.041

Craig, L., \& Mullan, K. (2011). How Mothers and Fathers Share Childcare: A Cross-National TimeUse Comparison. American Sociological Review, 76(6), 834-861. doi: $10.1177 / 0003122411427673$

Cravens, J. D., Whiting, J. B., \& Aamar, R. (2015). Why I stayed/left: An analysis of voices of intimate partner violence on social media. Contemporary Family Therapy, 37(4), 372-385. doi: 10.1007/s10591-015-9360-8

Di Grande, L., Perrier, M. P., Lauro, M. G., \& Contu, P. (2000). Alcohol use and correlates of binge drinking among university students on the Island of Sardinia, Italy. Substance Use and Misure, 35(10), 1471-1483.

Edwards, K. M., Turchik, J. A., Dardis, C. M., Reynolds, N. \& Gidycz, C. A. (2011). Rape Myths: History, Individual and Institutional-Level Presence, and Implications for Change. Sex Roles, 65, 761-773. doi: 10.1007/s11199-011-9943-2

Eurobarometer (2015). Gender equality. Report. Special Eurobarometer 428 / Wave EB82.4 - TNS Opinion \& Social. Retrieved from http://ec.europa.eu/public_opinion/index_en.htm

Eyssel, F. A., \& Bohner, G. (2011). Schema effects of rape myth acceptance on judgments of guilt and blame in rape cases: The role of perceived entitlement to judge. Journal of Interpersonal Violence, 26(8), 1579-1605. doi: 10.1177/0886260510370593

Filippini, S. (2005). Relazioni perverse. La violenza psicologica nella coppia. Milano: Franco Angeli. FRA - European Union Agency for Fundamental Rights (2014). Violence against women: an EUwide survey. Main results. European Union Agency for Fundamental Rights. http://fra.europa.eu/en/publication/2014/violence-against-women-eu-wide-survey-mainresults-report 
Gerger, H., Gerger, H., Kley, H., Bohner, G., \& Siebler, F. (2007). The Acceptance of Modern Myths About Sexual Aggression (AMMSA) scale: Development and validation in German and English. Aggressive Behavior, 33, 422-440. doi: 10.13072/midss.440

Global Gender Gap Report (2018). World Economic Forum, Geneva, Switzerland.

Grubb, A., \& Turner, E. (2012), Attribution of blame in rape cases: A review of the impact of rape myth acceptance, gender role conformity and substance use on victim blaming. Aggression and Violent Behavior, 17(5), 443-452. doi: 10.1016/j.avb.2012.06.002

Helmus, L., Hanson, R. K., Babchishin, K. M., \& Mann, R. E. (2013). Attitudes supportive of sexual offending predict recidivism: A meta-analysis. Trauma, Violence, \& Abuse, 14, 3453. doi: $10.1177 / 1524838012462244$

Hinck, S. S., \& Thomas, R. W. (1999). Rape Myth Acceptance in College Students: How Far Have We Come? Sex Roles, 40, 815-832. doi: 10.1177/0886260510370593

Hingson, R. W., Zha, W., \& Weitzman, E. R. (2009). Magnitude of and Trends in Alcohol-Related Mortality and Morbidity Among U.S. College Students Ages 18-24, 1998-2005. Journal of Studies on Alcohol and Drugs, 16, 12-20. doi: 10.15288/jsads.2009.s16.12

Ho, E., \& Neville, H. (2004). Korean Rape Myth Acceptance Scale. Development and Validation of the Korean Rape Myth Acceptance Scale. The Counseling Psychologist, 32(2), 301-331.

Hu, L., \& Bentler, P. M. (1999). Cutoff criteria for fit indexes in covariance structure analysis: Conventional criteria versus new alternatives. Structural Equation Modeling, 6(1), 1-55. doi: $10.1080 / 10705519909540118$

Il Sole 24Ore (2019). La violenza, le denunce e gli stupri. Il femminicidio in Italia. Retrieved from https://www.infodata.ilsole24ore.com (4th may, 2019)

Istat - Italian National Institute of Statistics (2015). La violenza contro le donne. https://www.istat.it/it/archivio/161716 
Kamdar, Z. N., Kosambiya, J. K., Chawada, B. L., Verma, M., \& Kadia, A. (2017). Rape: Is it a lifestyle or behavioral problem?. Indian Journal of Psychiatry, 59, 77-82. doi: $10.4103 /$ psychiatry

Jones, M. E., Russell, R. L., \& Bryant, F. B. (1998). The Structure of Rape Attitudes for Men and Women: A Three-Factor Model. Journal of Research in Personality, 32, 331-350. doi: 10.1006/jrpe.1998.2217

Jost, J. T., \& Banaji, M. R. (1994). The role of stereotyping in system-justification and the production of false consciousness. British Journal of Social Psychology, 33(1), 1-27. doi: 10.1111/j.20448309.1994.tb01008.x

Jost, J. T., \& Kay, A. C. (2005). Exposure to benevolent sexism and complementary gender stereotypes: Consequences for specific and diffuse forms of system justification. Journal of Personality and Social Psychology, 88(3), 498-509. doi: 10.1037/0022-3514.88.3.498

Laghi, F., Baiocco, R., Lonigro, A., Capacchione, G., \& Baumgartner, E. (2012). Family functioning and binge drinking among Italian adolescents. Journal of Health Psychology, 17(8), 11321141. doi: $10.1177 / 1359105311430005$

Leanna, J. P., \& Mindy, J. E. (2017). Objectification and System Justification Impact Rape Avoidance Behaviors. Sex Roles, 76, 1-2, 11-120. doi: 10.1007/s11199-016-0660-8

Lee, S. (1999). Kangkant ongny om chuk’do- i keep’all-kwa tadangdo ky omj ung [Development and validity of Rape Myth Acceptance Scale]. Korean Journal of Social and Personality Psychology, 2, 131-148. doi: 10.1177/0886260509340536

Lerner, M. (1971). Observer's Evaluation of a Victim: Justice, Guilt, and Veridical Perception. Journal of Personality and Social Psychology, 20(2), 127-135. doi: 10.1037/h0031702

Lewin, K. (1946). Action Research and Minority Problems. Journal of Social Issues, 2, 34-46. doi: 10.1111/j.1540-4560.1946.tb02295.x 
Lonsway, K. A., \& Fitzgerald, L. F. (1995). Attitudinal antecedents of rape myth acceptance: A theoretical and empirical reexamination. Journal of Personality and Social Psychology, 68(4), 704-711. doi: 10.1037/0022-3514.68.4.704

Mann, R. E., Webster, S., Wakeling, H., \& Marshall, W. (2007). The measurement and influence of child sexual abuse supportive beliefs. Psychology, Crime, \& Law, 13, 443-458. doi: $10.1080 / 10683160601061141$

McMahon, S., \& Farmer, L. G. (2011). An Updated Measure for Assessing Subtle Rape Myths. Social Work Research, 35(2), 71-81.

Mouilso, E. R., \& Calhoun, K. S. (2013). The role of rape myth acceptance and psychopathy in sexual assault perpetration. Journal of Aggression, Maltreatment \& Trauma, 22(2), 159-174. doi: $10.1080 / 10926771.2013 .743937$

Navarro, J. C., \& Tewksbury, R. (2017). National Comparisons of Rape Myth Acceptance Predictors Between Nonathletes and Athletes From Multi-Institutional Settings. Sex Abuse, 1. doi: 1079063217732790

Nunes, K. L., Pettersen, C., Hermann, C. A., Looman, J.M., \& Spape, J. (2016). Does Change on the MOLEST and RAPE Scales Predict Sexual Recidivism?. Sexual Abuse: A Journal of Research and Treatment, 28(5), 427-447. doi 10.1177/1079063214540725

Olver, M. E., Nicholaichuk, T. P., Kingston, D. A., \& Wong, S. C. (2014). A multisite examination of sexual violence risk and therapeutic change. Journal of Consulting and Clinical Psychology, 82(2), 312. doi: $10.1037 / \mathrm{a} 0035340$

Payne, D. A., Lonsway, K. A., \& Fitzgerald, L. F. (1999). Rape myth acceptance: Exploration of its structure and its measurement using the Illinois Rape Myth Acceptance Scale. Journal of Research in Personality, 33(1), 27-68.

Reddy, L. N. (2018). An Experimental Study on the Impact of Informal Rape Myth Education to Alter Rape Myth Acceptance Scores in a Non-Student Sample. Dissertations and Theses. Paper 4460. 
Rollero, C., \& Tartaglia, S. (2018). The Effect of Sexism and Rape Myths on Victim Blame. Sexuality \& Culture, 1-11. doi: 10.1007/s12119-018-9549-8

Saenz, C. (2009). Integrating theories of sexual assault: Incorporating narcissistic reactance theory into the confluence model of sexual aggression. Michigan: Wayne State University (Unpublished Doctoral dissertation).

Schwendinger, J. R., \& Schwendinger, H. (1974). Rape Myths: In Legal, Theoretical, and Everyday Practice. Crime and Social Justice, 1, 18-26.

Selvatico, E. (2018). Colpa, vergogna e pudore nell'identità della vittima di violenza sessuale. Politics. Rivista di Studi Politici, 9(1) 65-84.

Stahl, T., Eek, D., \& Kazemi, A. (2010). Rape Victim Blaming as System Justification: The Role of Gender and Activation of Complementary Stereotypes. Social Justice Research, 23, 239-258. doi: 10.1007/s11211-010-0117-0

Steiger, J. H. (1980). Tests for comparing elements of a correlation matrix. Psychological Bulletin, 87(2), 245-251. doi: 10.1037/0033-2909.87.2.245

Stenning, P., Mitra-Kahn, T., \& Gunby, C. (2013). Sexual violence against female university students in the U.K.: A case study. Rivista di Criminologia, Vittimologia e Sicurezza, 7(2), 110-119.

Stephens, T., Kamimura, A., Yamawaki, N., Bhattacharya, H., Mo, W., Birkholz, R., Makomenaw, A., \& Olson, L.M. (2016). Rape Myth Acceptance Among College Students in the United States, Japan, and India. SAGE Open. https://doi.org/10.1177/2158244016675015

Tartaglia, S., Fedi, A., \& Miglietta, A. (2017). Family or friends: what counts more for drinking behaviour of young adults? / Familia o amigos: ¿qué pesa más en los hábitos de consumo de alcohol de los jóvenes?, Revista de Psicología Social, 32(1), 1-22. doi: 10.1080/02134748.2016.1248029

Tourangeau, R., Rips, L. J., \& Rasinski, K. A. (2000). The psychology of survey response. Cambridge, United Kingdom: Cambridge University Press. 
Tucker, L. R., \& Lewis, C. (1973). A reliability coefficient for maximum likelihood factor analysis. Psychometrika, 38, 1-10. doi: 10.1007/BF02291170

Xue, J., Fang, G., Huang, H., Cui, N., Rhodes, K. V., \& Gelles, R. (2016). Rape Myths and the CrossCultural Adaptation of the Illinois Rape Myth Acceptance Scale in China. Journal of Interpersonal Violence, 5. doi: 0886260516651315.

Warren, P., Swan, S., \& Allen, C. T. (2015). Comprehension of sexual consent as a key factor in the perpetration of sexual aggression among college men. Journal of Aggression, Maltreatment \& Trauma, 24(8), 897-913. doi: 10.1080/10926771.2015.1070232

WHO - World Health Organization (2009). Changing cultural and social norms that support violence. Retrieved from http://www.who.int/violenceprevention/publications/en/index.html

WHO - World Health Organization (2018). Violence against women. Retrieved from https://www.who.int/reproductivehealth/topics/violence/en/. 


\title{
Assessing Rape Myth Acceptance: a contribution to Italian validation of the Measure for
}

\author{
Assessing Subtle Rape Myth (SRMA-IT)
}

Table 1. Descriptive statistics of SRMA-IT items: mean and standard deviation

\begin{tabular}{l} 
McMahon \& Farmers' (2011) \\
\hline She asked for it \\
\hline 1. If a girl is raped while she is drunk, \\
she is at least somewhat responsible \\
for letting things get out of control. \\
2. When girls go to parties wearing \\
slutty clothes, they are asking for \\
trouble. \\
3. If a girl goes to a room alone with \\
a guy at a party, it is her own fault if \\
she is raped. \\
4. If a girl acts like a slut, eventually \\
she is going to get into trouble.
\end{tabular}

5. When girls are raped, it's often because the way they said "no" was unclear.

6. If a girl initiates kissing or hooking up, she should not be surprised if a guy assumes she wants to have sex.

Italian version

L'ha voluto lei

1.Una ragazza che viene violentata

$M \quad S D$

mentre è ubriaca ̀̀ in parte

responsabile per aver perso il controllo della situazione

2.Quando le ragazze indossano abiti

molto provocanti per andare a una

festa, stanno cercando guai

3.Se una ragazza va da sola con un

ragazzo in una stanza durante una

festa, è colpa sua se viene violentata

4. Se una ragazza si comporta come

una "sgualdrina", si sta mettendo nei guai

5. Quando le ragazze vengono

violentate, spesso è perché non hanno

saputo dire "no" in modo chiaro

6. Se una ragazza inizia a baciare o

1.58

.967

crea un contatto con un ragazzo, non

dovrebbe sorprendersi che lui pensi

che lei voglia fare sesso

He didn't mean to
7. When guys rape, it is usually
because of their strong desire for sex.
8. Guys don't usually intend to force
sex on a girl, but sometimes they get
too sexually carried away.

9. Rape happens when a guy's sex drive gets out of control.

Lui non intendeva

7. Quando i ragazzi commettono

$2.29 \quad 1.334$

violenza, di solito lo fanno a causa del

loro forte desiderio sessuale

8. I ragazzi di solito non intendono

$2.30 \quad 1.264$

forzare sessualmente una ragazza,

ma talvolta si lasciano trasportare

dal forte desiderio sessuale

9. Uno stupro si verifica quando un

ragazzo non riesce a controllare il proprio impulso sessuale

10. If a guy is drunk, he might rape someone unintentionally.

10. Se un ragazzo è ubriaco potrebbe

$2.14 \quad 1.256$

involontariamente violentare qualcuno

11. It shouldn't be considered rape if

a guy is drunk and didn't realise what he was doing.

11. Se un ragazzo è ubriaco e non si è

12. If both people are drunk, it can't

reso conto di quello che stava facendo

non si dovrebbe parlare di stupro be rape.

12. Se entrambe le persone son ubriache non può essere stupro

It wasn't really rape
13. If a girl doesn't physically resist
sex_even if protesting verbally-it
can't be considered rape.
Non è stato veramente stupro

13. Se una ragazza non mostra 
considerare stupro, anche se protesta verbalmente

14. If a girl doesn't physically fight 14 . Se una ragazza non si ribella

back, you can't really say it was rape.

fisicamente, non si può davvero dire che è stato stupro

15. A rape probably didn't happen if 15. Probabilmente non c'è stato the girl has no bruises or marks. stupro se una ragazza non ha lividi o segni

16. If the accused "rapist" doesn't 16. Se chi è accusato di essere uno have a weapon, you really can't call it a rape. "stupratore" non era armato, non si può realmente parlare di stupro

17. If a girl doesn't say "no" she can't claim rape.

17. Se una ragazza non dice "no", non può sostenere che vi sia stato uno stupro

She lied
18. A lot of times, girls who say they
were raped agreed to have sex and
then regret it.
Lei ha mentito

18. Molte volte le ragazze che dicono

$2.23 \quad 1.086$
di essere state violentate hanno accettato di avere rapporti sessuali di cui si sono poi pentite

19. Rape accusations are often used as a way of getting back at guys.

19. Le accuse di stupro sono spesso usate come modi per vendicarsi dei ragazzi

20. A lot of times, girls who say they were raped often led the guy on and then had regrets.

20. Molte volte le ragazze che dicono di essere state stuprate hanno lasciato fare il ragazzo e poi se ne sono pentite

21. A lot of times, girls who claim they were raped just have emotional problems.

21. Molte volte le ragazze che sostengono di essere state stuprate hanno problemi emotivi

22. Girls who are caught cheating on their boyfriends sometimes claim that 22. A volte le ragazze che vengono it was a rape. sorprese a tradire il proprio ragazzo sostengono di essere state stuprate 
Table 2. Exploratory factor analysis of SRMA-IT: Factor loadings

\begin{tabular}{cccc}
\hline She lied & $\begin{array}{c}\text { It Wasn't } \\
\text { Really Rape }\end{array}$ & $\begin{array}{c}\text { She asked } \\
\text { for it }\end{array}$ & $\begin{array}{c}\text { He didn't } \\
\text { mean to }\end{array}$ \\
\hline
\end{tabular}

20. A lot of times, girls who say they

were raped often led the guy on and

then had regrets.

19. Rape accusations are often used as a way of getting back at guys.

18. A lot of times, girls who say they

were raped agreed to have sex and

then regret it.

22. Girls who are caught cheating on

their boyfriends sometimes claim that

it was a rape.

21. A lot of times, girls who claim

they were raped just have emotional

problems.

16. If the accused "rapist" doesn't

have a weapon, you really can't call it

a rape.

15. A rape probably didn't happen if the girl has no bruises or marks.

14. If a girl doesn't physically fight back, you can't really say it was rape.

11. It shouldn't be considered rape if a guy is drunk and didn't realize what he

was doing. *

13. If a girl doesn't physically resist

sex-even if protesting verbally-it

can't be considered rape.

17. If a girl doesn't say “no” she can't

claim rape.

12. If both people are drunk, it can't

be rape.

4. If a girl acts like a slut, eventually

she is going to get into trouble.

3. If a girl goes to a room alone with a guy at a party, it is her own fault if she is raped.

2. When girls go to parties wearing slutty clothes, they are asking for trouble.

1. If a girl is raped while she is drunk, she is at least somewhat responsible

for letting things get out of control.

6. If a girl initiates kissing or hooking

up, she should not be surprised if a

guy assumes she wants to have sex.

5 . When girls are raped, it's often because the way they said "no" was unclear. 
7. When guys rape, it is usually

because of their strong desire for sex.

8. Guys don't usually intend to force

sex on a girl, but sometimes they get

too sexually carried away.

9. Rape happens when a guy's sex

drive gets out of control.

10. If a guy is drunk, he might rape

$-.42$

someone unintentionally.

Note. Loadings below .30 are omitted.

* Items not used in the Confirmatory Factor Analysis. 
Table 3. Confirmatory factor analysis of SRMA-IT: Factor loadings and Error variances

\begin{tabular}{cccc}
\hline \multicolumn{4}{c}{ Factor Loadings } \\
\hline She lied & It Wasn't & She & He \\
Really & asked for & didn't \\
Rape & it & mean to
\end{tabular}

Error

variances

20. A lot of times, girls who say they

.91

.16

were raped often led the guy on and

then had regrets.

19. Rape accusations are often used

as a way of getting back at guys.

18. A lot of times, girls who say they

were raped agreed to have sex and

then regret it.

22. Girls who are caught cheating on

their boyfriends sometimes claim

that it was a rape.

21. A lot of times, girls who claim

they were raped just have emotional problems.

16. If the accused "rapist" doesn't

have a weapon, you really can't call

it a rape.

15. A rape probably didn't happen if

the girl has no bruises or marks.

14. If a girl doesn't physically fight

.89

back, you can't really say it was

rape.

13. If a girl doesn't physically resist

sex - even if protesting verbally - it

can't be considered rape.

17. If a girl doesn't say "no" she

can't claim rape.

4. If a girl acts like a slut, eventually she is going to get into trouble.

3 . If a girl goes to a room alone with a guy at a party, it is her own fault if she is raped.

2. When girls go to parties wearing slutty clothes, they are asking for trouble.

1. If a girl is raped while she is drunk, she is at least somewhat responsible for letting things get out of control.

6. If a girl initiates kissing or

hooking up, she should not be

surprised if a guy assumes she wants to have sex. 
5. When girls are raped, it's often

because the way they said "no" was unclear.

7. When guys rape, it is usually

because of their strong desire for sex.

8. Guys don't usually intend to force

sex on a girl, but sometimes they get

too sexually carried away.

9. Rape happens when a guy's sex 
Table 4. Scale scores for Males $(\mathrm{N}=586)$ and Females $(\mathrm{N}=1378)$ : Mean, Standard Deviation, $\mathrm{T}$ and Cohen's d values

\begin{tabular}{lcccc}
\hline & \multicolumn{2}{c}{ M (SD) } & & \\
& & Females & & $\begin{array}{c}\text { Effect size } \\
\text { Cohen's } \boldsymbol{d}\end{array}$ \\
\hline She asked for & $2.20(.83)$ & $1.74(.71)$ & $12.40^{* *}$ & .60 \\
He didn't mean to & $2.56(1.01)$ & $2.14(.97)$ & $8.50^{* *}$ & .42 \\
It wasn't really rape & $1.59(.71)$ & $1.35(.68)$ & $6.93^{* *}$ & .35 \\
She lied & $2.39(.96)$ & $2.00(.90)$ & $9.07^{* *}$ & .42 \\
\hline$* * p<.01$ & & & &
\end{tabular}

